rev.relac.int.estrateg.segur.6(2):179-194,2011

\title{
LA LEY DE JUSTICIA Y PAZ EN COLOMBIA: LA CONFIGURACIÓN DE UN SUBCAMPO JURÍDICO-POLÍTICO Y LAS LUCHAS SIMBÓLICAS POR LA INCLUSIÓN*
}

\author{
Mariana Delgado Barón**
}

\section{RESUMEN}

El Proceso de Justicia y Paz puede ser concebido como un campo jurídico- político que ha asignado tanto a las víctimas como a los victimarios del conflicto armado no sólo un lugar diferenciado, sino también, los recursos simbólicos, sociales, políticos y materiales, a través de los cuales se valida o se cuestiona este campo, y en especial, las estrategias jurídicas y políticas de clasificación impuestas desde el lugar privilegiado del Estado. En este sentido, el espacio jurídico- político

* Este artículo recoge algunas de las reflexiones preliminares contenidas en mi tesis doctoral titulada "Las víctimas como sujetos políticos en el proceso de Justicia Y Paz en Colombia: discursos imperantes y disruptivos en torno a la reconciliación, la verdad, la justicia y la reparación" para obtener el grado de Doctora en Ciencias Sociales con mención en sociología de la Facultad Latinoamericana de Ciencias Sociales- FLACSO, sede México.

** Politóloga Universidad de Los Andes (Bogotá- Colombia), Magister en Ciencia Política Universidad de Los Andes (Bogotá- Colombia), Magister en Política Internacional Universidad de Birmingham (Birmingham- Inglaterra), Doctora en Investigación en Ciencias Sociales con mención en sociología Flacso (México), actualmente Profesora Asociada de tiempo completo del Programa de Relaciones Internacionales de la Universidad de Bogotá Jorge Tadeo Lozano; mariana.delgado@flacso.edu.mx , mariana.delgadob@utadeo.edu.co. 
configurado a partir de la Ley 975 de 2005, ha producido discursos dominantes, pero también disruptivos o de ruptura en torno al tema de la reconciliación, que permiten identificar formas concretas de constitución de sujetos políticos y la lucha de estos por ser visibilizados y reconocidos.

Palabras clave: Ley de Justicia y Paz, reconciliación, discursos dominantes y disruptivos, campo político, víctimas, sujetos políticos.

\begin{abstract}
The Justice and Peace Process may be considered a judicial-political field in which victims and perpetrators of the armed conflict have been assigned not only a particular place, but also specific symbolic, social, political and material resources for validating or questioning that field, and specially the judicial and political categorizing strategies imposed from the privileged place of the State. In this sense, the judicial-political space configured by the Law 975 of 2005 has produced dominant discourses, but it also has produced disruptive ones associated with the subject of reconciliation, that allow identification of concrete forms of constitution of political subjects and their struggle for recognition.
\end{abstract}

Key words: Justice and Peace Law, reconciliation, dominant and disruptive discourses, political field, victims, political subjects.

\title{
RESUMO
}

O Processo de Justiça e Paz pode ser concebido como um campo jurídico-político que institui tanto às vítimas como aos perpetradores do conflito armado não só um lugar diferenciado, mas também, os recursos simbólicos, sociais, políticos e materiais, através do quais valida-se o questiona-se esse campo e, em particular, as estratégias jurídicas e políticas de classificação impostas desde o lugar privilegiado do Estado. Deste modo, o espaço jurídico-político formado a partir da Lei 975 de 2005, tem produzido discursos dominantes, mas também de ruptura em torno da questão da reconciliação, que permite identificar maneiras concretas de constituição de sujeitos políticos e de suas lutas por se tornarem visíveis e reconhecidos.

Palavras chave: Lei de Justiça e Paz, reconciliação, discursos dominantes e de ruptura, campo político, vítimas, sujeitos políticos. 


\section{INTRODUCCIÓN}

Como bien se señaló como nota al pie, el presente artículo recoge algunas de las reflexiones preliminares y puertas de entrada al problema de investigación abordado en mi tesis doctoral, que se centra en el análisis de las víctimas como sujetos políticos en el Proceso de Justicia y Paz en Colombia; al respecto, sólo quisiera señalar algunas generalidades de la misma.

La tesis se centra en abordar, desde el análisis del discurso, la pregunta sobre cómo la noción de víctima ha sido construida, deconstruida y reelaborada a partir de la forma jurídica contenida en la Ley 975 de 2005, y en este sentido, por el tipo de efectos políticos que se han derivado de dicha forma. En concreto, el interés central de la tesis es indagar por el tipo de sujetos políticos que la ley ha posibilitado constituir, y por las formas en que la noción de víctima ha sido apropiada e instrumentalizada por víctimas y victimarios del conflicto armado en Colombia.

En esta misma dirección, la pregunta por la noción de víctima contenida en la ley y que permea el proceso de Justicia y Paz, es también una pregunta por los espacios políticos y sociales que ésta ha posibilitado, como consecuencias no esperadas por sus promotores, como efectos no deseados o buscados. Es importante señalar que la(s) apropiación(es) de la noción de víctima que hacen los diferentes actores ha producido sujetos políticos que se posicionan en los espacios político y social, y en este sentido, de la forma jurídica contenida en la ley, se despliegan diferentes re-elaboraciones e incluso se politizan (y se despolitizan también), determinados espacios en los que se producen distintos procesos de subjetivación.

Por otra parte, la investigación se apoya en algunos de los postulados del Análisis Crítico del Discurso (ACD), que hacen referencia al papel que juega el discurso en la configuración del orden social (y la concepción de toda configuración social como un constructo significativo en términos discursivos). De tal forma, se reconoce que el discurso es una práctica social que plantea o supone una extensión analítica de lo político, sin limitar el discurso a un acto exclusivamente lingüístico, sino que por el contrario, se extiende también a lo extralingüístico. De esta manera, se concibe el discurso como un mecanismo privilegiado que permite a los sujetos políticos estructurar un espacio específico para configurar y fortalecer sus identidades individuales y colectivas, también se constituye en un instrumento o mecanismo y recurso de poder que refleja la naturaleza de la lucha asociada con la actividad política. A través del discurso político se manifiesta la tensión relacionada con los procesos de configuración de los sujetos y de sus identidades, que a su vez, constituye un espacio de conflicto y de confrontación entre los diferentes sujetos como requisito para poder identificar dos comunidades: el nosotros y el ellos.

La perspectiva que se adopta con el ACD se centra en prestar especial atención a aquellos procesos que generan exclusión y dominación, así como los que buscan generar resistencia. El discurso se concibe entonces como una forma de acción y práctica social que resalta el carácter 
discursivo de los procesos sociales, o en otras palabras, como un acto social, que trasciende la idea del texto y que se extiende a formas de interacción y recreación de la realidad.

Es importante aclarar que si bien en la tesis se realiza el trabajo de señalar e incluir los desarrollos de la noción de víctima en los planos nacional e internacional, y asimismo de inscribir la discusión sobre el empleo de los mecanismos de la justicia transicional en el caso colombiano, bajo los que se busca cobijar el proceso de Justicia y Paz, en este documento no se pretende retomar dichas discusiones.

Ahora bien, en el año de 2005 el Congreso de la República de Colombia aprobó la Ley 975, conocida como la Ley de Justicia y Paz, que tiene por objetivo manifiesto: "facilitar los procesos de paz y la reincorporación individual o colectiva a la vida civil de miembros de grupos armados al margen de la ley, garantizando los derechos de las víctimas a la verdad, la justicia y la reparación" ${ }^{\prime \prime}$. De forma explícita la Ley reconoce a quiénes se debe considerar como víctimas del conflicto, y establece los derechos a los que éstas tienen acceso; asimismo, la Ley estipula los "requisitos de elegibilidad" para la desmovilización individual y colectiva ${ }^{2}$ (Artículos 4으, 5으, 6으, $\left.7^{\circ}, 8^{\circ},{ }^{\circ} 10^{\circ}, 11^{\circ}\right)$.

Con la Ley de Justicia y Paz el gobierno colombiano busca dar un sustento jurídico al proceso de desmantelamiento de las estructuras de los grupos armados ${ }^{3}$ al margen de la ley, haciendo un especial énfasis en el carácter de reconciliación que implican las desmovilizaciones, como un mecanismo adoptado para contribuir a la "consecución de la paz". De este modo, la Ley estipula que dentro del proceso de reconciliación nacional es necesario el derecho a la verdad, la justicia y la reparación para las víctimas.

En este sentido, el artículo se orienta a analizar desde la lógica de los campos y del espacio social, al igual que bajo los conceptos del capital y del poder simbólico contenidos en la propuesta de Bourdieu, las dinámicas de inclusión/ exclusión, visibilidad/ invisibilidad que permean el universo de las víctimas del conflicto armado en Colombia, al igual que las dinámicas por la lucha política y simbólica que ha implicado el debate alrededor de los derechos de las víctimas a la verdad, la justicia y la reparación, y por el reconocimiento de las víctimas de todos los actores involucrados en el conflicto, incluyendo las del Estado. Así mismo, con el escrito también se pretende dar cuenta del poder de la nominación y clasificación como un poder simbólico, que para el caso particular se encuentra reflejado en el monopolio estatal para decidir a

1. Artículo 1, Ley 795 de 2005.

2. "Se entiende por desmovilización el acto individual o colectivo de dejar las armas y abandonar el grupo armado organizado al margen de la ley, realizado ante autoridad competente" (Art. 9o).

3. "Se entiende por grupo armado organizado al margen de la ley, el grupo de guerrilla o de autodefensas, o una parte significativa e integral de los mismos como bloques, frentes u otras modalidades de esas mismas organizaciones". Art. 1, Ley 795. 
quién se reconoce o no dentro del universo de las víctimas, y para tal efecto, se parte del supuesto que reconoce en el lenguaje a un "instrumento o soporte de las relaciones de poder" (Bourdieu, 1995: 101), en concordancia con el ACD, que concibe al discurso político como un mecanismo privilegiado que permite a los sujetos políticos estructurar un espacio específico para configurar y fortalecer sus identidades individuales y colectivas, pero que sobretodo, implica un espacio de lucha en el que se reflejan las relaciones de poder, de dominio, y también de resistencia.

El presente artículo, se encuentra organizado de la siguiente forma: en el primer apartado se realiza una breve contextualización sobre el Proceso de Justicia y Paz que se viene adelantando en Colombia a partir del año 2005 y se hace un especial énfasis del proceso como un campo jurídico- político en el que se ha presentado una constante lucha entre víctimas y victimarios, por el pleno reconocimiento de las primeras con sus consecuentes derechos; en el segundo apartado se establece una aproximación al universo de las víctimas del conflicto armado colombiano según la Ley de Justicia y Paz, teniendo en cuenta las lógicas de inclusión/ exclusión y visibilidad/ invisibilidad que dan forma al debate sobre quién pertenece y quién es reconocido como parte de dicho universo, y a las luchas políticas y simbólicas que se dan en este subcampo; en la tercera sección se enfatiza en el poder de la nominación y clasificación de las víctimas, como un mecanismo que tiene el propósito de continuar una lógica en particular del campo de la política en Colombia y en especial del campo jurídico- político que se forma a partir de la Ley de Justicia y Paz, que también posibilita la emergencia de discursos disruptivos o de resistencia que han permitido en algunos sectores de las víctimas a adquirir poder simbólico y social. Por último, en la sección final se mencionarán algunas consideraciones finales relacionadas con los temas abordados.

\section{EL PROCESO DE JUSTICIA Y PAZ: LAS LÓGICAS DE UN CAMPO JURÍDICO- POLÍTICO}

En su manifestación explícita, la Ley 975 busca facilitar la reconciliación nacional, generar acuerdos de carácter humanitario y garantizar los derechos de las víctimas frente a la administración de la justicia; por otra parte, también busca facilitar la reincorporación de los desmovilizados a la vida civil, contribuir al desmantelamiento de las estructuras de los grupos armados al margen de la ley y generar la posibilidad de acceso al beneficio de una pena alternativa ${ }^{4}$, para el caso de los desmovilizados, una vez se cumplan con los requisitos de colaborar con la justicia y reparar a las

4. La pena alternativa "consiste en privación de la libertad por un periodo mínimo de cinco (5) años y no superior a ocho (8) años, tasada de acuerdo con la gravedad de los delitos y su colaboración efectiva en el esclarecimiento de los mismos. Para tener derecho a la pena alternativa se requerirá que el beneficiario se comprometa a contribuir con su resocialización a través del trabajo, estudio o enseñanza durante el tiempo que permanezca privado de su libertad, y a promover actividades orientadas a la desmovilización del grupo armado al margen de la ley al cual perteneció" (Artículo 29). 
víctimas. La idea o noción de la reconciliación que se suscribe en la Ley de Justicia y Paz, y que por lo tanto permea todo el proceso de desmonte de las estructuras de los grupos armados al margen de la ley, la consiguiente reinserción de los desmovilizados y la búsqueda y garantía de los derechos de las víctimas a la verdad, la justicia y la reparación, implica por una parte la "voluntad" de los desmovilizados de colaborar con la "consecución de la paz nacional", y por otro lado, el compromiso por parte de las "distintas autoridades" de hacer cumplir "las medidas de satisfacción y garantías de no repetición" que se encuentran en concordancia con los derechos de las víctimas, y el "respeto al debido proceso y las garantías judiciales de los procesados" (Artículo 4\%), contemplados en dicha Ley.

En este sentido, el proceso de Justicia y Paz se enmarca en un "macro- discurso" de la reconciliación que no sólo abarca la posición del gobierno, o el discurso gubernamental, como un discurso dominante, sino que también permite la inserción de los discursos de víctimas y victimarios, ya sea como continuidades del discurso imperante, o como respuestas disruptivas y de resistencia a éste.

Por otro lado, con la Ley de Justicia y Paz se establece jurídicamente a quién se reconoce como víctima, y por lo tanto, a quién se le reconocen los derechos a la verdad, la justicia y la reparación, dicho reconocimiento es problemático puesto que deja por fuera de este universo a las víctimas de crímenes de Estado, cuya lucha política se ha centrado precisamente en adquirir ese estatus que otorga la Ley. Es así como la formulación e implementación de la Ley supone y reconoce un tipo particular de víctima y también visibiliza a las víctimas de una forma en concreto, a la par que excluye e invisibiliza a determinados sectores que también han sido victimizados.

La Ley de Justicia y Paz se convierte en el marco normativo que ampara el proceso de desarme, desmovilización y reinserción, tanto colectiva como individual, de los integrantes de los grupos armados al margen de la ley, y a su vez se constituye en el instrumento legal para que las víctimas de dichos grupos accedan a la verdad, la justicia y la reparación. Es importante destacar que con el proceso de Justicia y Paz, que se inicia con la puesta en marcha de la Ley 975, se ha buscado una suerte de concordancia entre el objetivo último que es la reconciliación con el objetivo estratégico que se encuentra detrás de las desmovilizaciones: esto quiere decir que la tensión permanente que se presenta entre la concepción de la Ley como un mecanismo para desmovilizar por una parte, y como un instrumento que posibilita la reconciliación nacional por otro lado, ha incidido en que esta sea concebida desde los sectores de oposición al gobierno y desde las asociaciones de víctimas, como un medio que solo privilegia a los victimarios y que no reconoce adecuadamente a las víctimas y sus derechos.

En términos más concretos, respecto al derecho a la justicia, la Ley contempla el deber que tiene el Estado: 
[...] de realizar una investigación efectiva que conduzca a la identificación, captura y sanción de las personas responsables por delitos cometidos por los miembros de grupos armados al margen de la ley; asegurar a las víctimas de esas conductas el acceso a recursos eficaces que reparen el daño infligido, y tomar todas las medidas destinadas a evitar la repetición de tales violaciones (Artículo 6ㅇ).

Con relación al derecho a la verdad, la Ley establece que:

[...] la sociedad, y en especial las víctimas, tienen el derecho inalienable, pleno y efectivo de conocer la verdad sobre los delitos cometidos por grupos organizados al margen de la ley, y sobre el paradero de las víctimas de secuestro y desaparición forzada" (Artículo 7으).

Por último, sobre el derecho a la reparación:

[...] comprende las acciones que propendan por la restitución, indemnización, rehabilitación, satisfacción; y las garantías de no repetición de las conductas, [entendiendo por] reparación simbólica toda prestación realizada a favor de las víctimas o de la comunidad en general que tienda a asegurar la preservación de la memoria histórica, la no repetición de los hechos victimizantes, la aceptación pública de los hechos, el perdón público y el restablecimiento de la dignidad de las víctimas" (Artículo 8으.

Con más de seis años de aplicación de la Ley de Justicia y Paz, las críticas por parte de las asociaciones de víctimas y organizaciones defensoras de derechos humanos han sido una constante. Estas residen en la falta de mecanismos más allá de las disposiciones de la Ley para promover y garantizar los derechos de las víctimas, como bien se señaló en párrafos anteriores ${ }^{5}$.

Mencionado esto, se puede sostener la idea que concibe al Proceso de Justicia y Paz como una especie de campo jurídico- político, para Bourdieu el campo es:

[...] una red o configuración de relaciones objetivas entre posiciones (...), que se definen objetivamente en su existencia y en las determinaciones que impo-

5. Sin embargo, es de aclarar que con el cambio de gobierno en el 2010, el Presidente Juan Manuel Santos promovió una Ley de Víctimas: "por la cual se dictan medidas de atención, asistencia y reparación integral a las víctimas del conflicto armado interno y se dictan otras disposiciones" para el goce efectivo de los derechos de las víctimas a la verdad, la justicia y la reparación con garantía de no repetición, "de modo que se reconozca su condición de víctimas y se dignifique a través de la materialización de sus derechos constitucionales" (Artículo 1, Ley 1448 de 2011), 
nen a sus ocupantes, ya sean agentes o instituciones, por su situación actual y potencial en la estructura de la distribución de las diferentes especies de poder, y, de paso, por sus relaciones objetivas con las demás posiciones (Bourdieu, 1995: 64).

Así, con el Proceso de Justicia y Paz se ha configurado un campo social, jurídico y político ${ }^{6}$ que asigna un lugar determinado a las víctimas y a los victimarios del conflicto armado, y que otorgaun tipo de capital diferenciado, a la vez que ha producido y reproducido no sólo lógicas y dinámicas de dominación, exclusión y subordinación, sino también de resistencia y de movilización que se materializan en construcciones discursivas y acciones sociales en contra de la imposición de las disposiciones del espacio que se formulan en la Ley. De esta manera, Justicia y Paz puede concebirse entonces como un campo:

"en tanto que estructura de relaciones objetivas posiciones de fuerza, sostiene y orienta las estrategias por las cuales los ocupantes de esas posiciones buscan, individual o colectivamente, salvaguardar o mejorar su posición e imponer el principio de jerarquización más favorable a sus propios productos. Dicho de otro modo, las estrategias de los agentes dependen de su posición en el campo, es decir en la distribución del capital específico, y de la percepción que tienen del campo, es decir de su punto de vista sobre el campo en tanto que vista tomada a partir de un punto dentro del campo" (Bourdieu; 1993: 7).

En este campo constituido por el Proceso de Justicia y Paz, los diferentes participantes o las diversas partes involucradas cuentan con tipos y cantidades de capital diferenciados, ya sea de tipo político, social, económico, e incluso simbólico, que a su vez les permite o no ejercer poder en los límites del campo. De esta forma, el capital entendido como "un factor eficiente en un campo dado" es lo que posibilita a las diferentes partes "ejercer un poder, una influencia, por tanto existir en un determinado campo, en vez de ser una simple cantidad deleznable" (Bourdieu,

6. Son reconocidas las dimensiones cultural y social que se presentan en el campo del proceso de Justicia y Paz, sin embargo, se consideran únicamente la dimensión política y jurídica del campo de Justicia y Paz, debido al interés en analizar las interacciones entre la política y lo jurídico a partir de los procesos de subjetivación. En este punto es clave señalar, como lo menciona García (2010), que las conexiones que pueden existir entre el campo de la política y el campo jurídico son múltiples y variadas a la vez que "mutuamente constitutivas". El derecho se configura como un "campo social" en el que se presentan disputas y luchas "por la interpretación de las formas jurídicas" y por el dominio exclusivo de un poder simbólico que se encuentra en los textos jurídicos y en general en las formas jurídicas (García; 2010: 21- 22). Este poder simbólico propio del derecho y de sus formas jurídicas nos permite hablar de una violencia simbólica que es ejercida desde el campo de lo jurídico; "controlar el derecho es controlar la sociedad", y la lucha por el control del campo jurídico nos lleva a la idea de este campo como un espacio de disputa por establecer los significados de las formas y textos jurídicos. Este hecho se extiende al campo político y genera efectos políticos, puesto que las decisiones jurídicas producen efectos en la "distribución de poder y de bienes que se encuentran en el campo político" (García; 2010: 22). 
1995: 65). En el caso de los victimarios, estos cuentan con el poder político derivado de una Ley que les otorga considerables beneficios y oportunidades para la desmovilización; y en el caso del Estado, el poder jurídico, y por supuesto político, que no sólo se hace presente en el ejercicio de las facultades para clasificar a las víctimas, sino que también surge al momento de autoexcluirse del conjunto de victimarios.

Sin embargo, las víctimas, y en especial aquellas que se encuentran agrupadas en asociaciones, han adquirido en la lucha por el reconocimiento a sus derechos, una suerte de capital simbólico que si bien no constituye un poder que busque la dominación en el campo constituido por el Proceso de Justicia y Paz, si es un capital que les ha permitido movilizar a sectores de la sociedad en pro de una visión más justa y equitativa respecto a los derechos y el pleno reconocimiento de las víctimas como sujetos políticos y sociales.

El campo jurídico- político que se ha configurado a partir de la formulación y ejecución de la Ley de Justicia y Paz es un "espacio social" en el que víctimas y victimarios se han constituido no sólo como sujetos jurídicos, sino como sujetos políticos que se relacionan en este espacio, que a la vez está "inscripto en las estructuras espaciales y las estructuras mentales, que son en parte el producto de la incorporación de las primeras", en otras palabras, el Proceso de Justicia y Paz como espacio social "es uno de los lugares donde se afirma y ejerce el poder" (Bourdieu, 2007a: 122).

Es importante señalar que a partir de la concepción del proceso de Justicia y Paz como un espacio social, la lucha por los posicionamientos se da en torno a los derechos de las víctimas frente a la responsabilidad que tienen los victimarios de contar la verdad de los crímenes y reparar integralmente a las víctimas, y alrededor del papel que deben jugar estas últimas respecto a la búsqueda de la reconciliación en el país. Del mismo modo, la lucha por los posicionamientos y por la reconfiguración del campo como espacio social, se manifiesta a partir de la misma búsqueda que emprenden las víctimas por su pleno reconocimiento, como es el caso del Movimiento de Víctimas de Crímenes de Estado (MOVICE), que ha sabido aprovechar su extensa red de apoyo o soporte alrededor del tema de las víctimas y la reivindicación de sus derechos. Con el MOVICE, se ve claramente cómo "las estrategias de los agentes dependen de su posición en el campo", de acuerdo a lo mencionado por Bourdieu; particularmente, la estrategia de movilización social y política emprendida por el MOVICE ha dependido de su ubicación o localización en el espacio social configurado por la Ley de Justicia y Paz, incluso, desde su posición de no- reconocimiento jurídico, han liderado la lucha política y jurídica por su plena inclusión en el proceso. De esta forma, el campo como espacio social "es escenario de relaciones de fuerza y de luchas encaminadas a transformarlas $y$, por consiguiente, el sitio de un cambio permanente" (Bourdieu, 1995: 69).

Por otro lado, si se parte de la idea de un espacio social, jurídico y político, que "se presenta bajo la forma de agentes provistos de propiedades diferentes y sistemáticamente ligadas 
entre sí" (Bourdieu, 2007b: 134), el mismo alcance de la Ley y las lógicas que ha adoptado el Proceso de Justicia y Paz le han otorgado tanto a víctimas como a victimarios no solo una posición diferenciada y concreta en el campo, sino sobre todo la dotación de capitales de diferente naturaleza que los agentes emplean ya sea para posicionase en el espacio social o para emprender una reconfiguración del mismo.

\section{SOBRE EL UNIVERSO DE LAS VÍCTIMAS Y LAS LUCHAS POLÍTICAS Y SIMBÓLICAS POR LA INCLUSIÓN}

La figura de víctima que reconoce la Ley no se extiende a aquellas que lo han sido por parte de agentes del Estado como se ha mencionado en párrafos anteriores ${ }^{7}$. De esta forma, bajo la Ley 975 de 2005 se presenta el caso de las víctimas reconocidas y de aquellas que ni siquiera han sido contempladas como tal. Este fenómeno implica a su vez que por una parte la Ley, y el uso que se ha hecho de ésta, han posibilitado en determinados casos la movilización social y política, o para ser más precisos la activación de esa movilización, y en otros casos la ha estancado o imposibilitado. Del mismo modo, con la Ley se da el reconocimiento de un determinado tipo de sujeto jurídico que puede derivar en la constitución de sujetos políticos. La existencia de un universo de víctimas, variado y diverso, que deja por fuera a determinados tipos de víctimas, pero que incluye a otras, se encuentra permeado por dinámicas de marginalización, exclusión, invisibilidad, discriminación, estigmatización y desconocimiento. Encontramos también un problema de instrumentalización de las víctimas, particularmente por parte del gobierno, como una estrategia para demostrar avances respecto a la aplicación de la Ley de Justicia y Paz. Se emplea el nombre de las víctimas para indicar que existe una preocupación del gobierno por el tema de sus derechos. La instrumentalización de las víctimas para tales fines es una forma de continuar empleando mecanismos de re- victimización, que ponen de manifiesto el empleo de

7. Según la Ley 975, "se entiende por víctima la persona que individual o colectivamente haya sufrido daños directos tales como lesiones transitorias o permanentes que ocasionen algún tipo de discapacidad física, psíquica y/o sensorial (visual y/o auditiva), sufrimiento emocional, pérdida financiera o menoscabo de sus derechos fundamentales. Los daños deberán ser consecuencia de acciones que hayan transgredido la legislación penal, realizadas por grupos armados organizados al margen de la ley. También se tendrá por víctima al cónyuge, compañero o compañera permanente, y familiar en primer grado de consanguinidad, primero civil de la víctima directa, cuando a esta se le hubiere dado muerte o estuviere desaparecida. La condición de víctima se adquiere con independencia de que se identifique, aprehenda, procese o condene al autor de la conducta punible y sin consideración a la relación familiar existente entre el autor y la víctima. Igualmente se considerarán como víctimas a los miembros de la Fuerza Pública que hayan sufrido lesiones transitorias o permanentes que ocasionen algún tipo de discapacidad física, psíquica y/o sensorial (visual o auditiva), o menoscabo de sus derechos fundamentales, como consecuencia de las acciones de algún integrante o miembros de los grupos armados organizados al margen de la ley. Así mismo, se tendrán como víctimas al cónyuge, compañero o compañera permanente y familiares en primer grado de consanguinidad, de los miembros de la fuerza pública que hayan perdido la vida en desarrollo de actos del servicio, en relación con el mismo, o fuera de él, como consecuencia de los actos ejecutados por algún integrante o miembros de los grupos organizados al margen de la ley" (Art. 5우). 
las víctimas como una estrategia, incluso de "marketing político", en donde se desconoce el carácter moral y el componente ético que encierra la lucha política del movimiento de víctimas.

Estas dinámicas persistentes de re- victimización, discriminación, marginación y exclusión que siguen padeciendo muchas de las víctimas, refleja a su vez un universo que dista de ser homogéneo, y que por el contrario llega a "catalogar" o "categorizar" a las víctimas según su condición y origen social; hecho que repercute también en los imaginarios y "concepciones" políticas y sociales que se forjan en la sociedad respecto a la población desplazada, los secuestrados, los desaparecidos y los sobrevivientes, por nombrar algunos ejemplos.

En esta misma dirección, la complejidad del conflicto armado colombiano, que en parte se refleja por la existencia de varios actores armados, ha derivado en la existencia de un variado universo de víctimas, y en las posibilidades de activación de las víctimas como sujetos políticos y sociales. En este sentido, la constitución o no de las víctimas como sujetos políticos, que trascienden la categoría de testigo, se encuentra determinada por el lugar que ocupan en este universo, y por ende por el reconocimiento o no que otorga la misma Ley. Ahora bien, la constitución de las víctimas en sujetos políticos es un proceso que se nutre también del lugar que ha sido asignado a las víctimas en el orden social por la misma sociedad, en otras palabras, la imagen y la concepción que la sociedad tiene de las víctimas determina a su vez si estas serán aceptadas como miembros en igualdad, en cuanto a ciudadanos con plenos derechos.

Los criterios de distinción y clasificación que realiza la Ley respecto al universo de víctimas han tenido efectos en la constitución del campo político que ha tomado forma a partir del Proceso de Justicia y Paz, particularmente, en relación con la constitución de las víctimas como sujetos políticos; es decir, la Ley permitió la configuración de determinados sujetos políticos que se constituyen a partir del reconocimiento que hace la misma a la víctima y el desmovilizado como sujetos jurídicos ${ }^{8}$.

Respecto a estos problemas que despierta el debate alrededor de los derechos de las víctimas, Sarmiento (2008) señala que el universo limitado de las víctimas que se plantea en la Ley, establece un trato diferenciado para víctimas de agentes del Estado y adicionalmente sólo reconoce directamente como víctimas aquellas cuyos derechos hayan sido vulnerados antes de que la ley hubiera sido aprobada, "dejando por fuera a futuras víctimas, como si el conflicto armado interno hubiese ya terminado" (Sarmiento, 2008).

8. Con esto no se pretende desconocer que desde antes de la puesta en marcha de la ley de justicia y paz ha habido desmovilizados y víctimas, sino que por el contrario se resalta la particular forma en que éstos son concebidos a partir de la misma.

9. Por otro lado, en el año 2007, dos años después de promulgada la Ley 975, el Senador Juan Fernando Cristo del Partido Liberal, opositor del gobierno de Uribe, lanza la iniciativa del proyecto de Ley 157 centrado en el tema de las reparaciones a las víctimas del conflicto. El proyecto de Ley 157 de 2007 "por la cual se dictan medidas de protección 
Adicionalmente, el principio de buena fe que cobijaba a las víctimas sobre su "status" se reemplaza por el deber que tienen las víctimas para ser reconocidas como tal, de certificar su condición ante el gobierno y así poder ser reparadas, es así como la victimización es constante cuando las víctimas necesitan "probar" que lo han sido para acceder a los derechos contemplados por la Ley. Respecto a la obtención de pruebas para "comprobar" que se ha sido víctima, la cita del psicoanalista Eissler empleada por Elster es pertinente:

Los pacientes, de hecho, deberían recibir compensación por la agitación y la degradación a que se vieron sometidos en el transcurso del proceso de reparación", en otras palabras, en el proceso de búsqueda de la reparación y del reconocimiento de los otros derechos, las víctimas se ven sometidas no sólo a "la agitación de recuerdos, agresiones y sentimientos", sino también y sobre todo a "nuevos males" que el mismo proceso de reparación genera, asociados con tener que llevar a cuestas "la carga de la prueba (Elster, 2006: 218- 219).

La lucha política y simbólica emprendida por las víctimas para ser adecuadamente reconocidas en el campo del proceso de Justicia y Paz se encuentra condicionada por el tipo de capital que estas detentan, debido a que "la capacidad de dominar el espacio (...) depende del capital poseído (...). Por lo tanto quienes carecen de capital son mantenidos a distancia, ya sea física o simbólicamente, de los bienes socialmente más escasos" (Bourdieu, 2007a: 122).

Por otra parte, si "el éxito de las luchas depende del capital poseído" y las posibilidades de apropiación de los diversos tipos de bienes materiales y no materiales se encuentran condicionadas por el lugar que se ocupa o que ha sido asignado en el espacio social, se puede afirmar que la condición de víctima, si bien no ha sido una garantía para ser reconocida por el Estado y por lo tanto para acceder a los derechos a la verdad, justicia y reparación, si ha hecho posible que las víctimas se conviertan o sean consideradas por la sociedad como "sujetos de derecho y de justicia, de verdad y de memoria", que al mismo tiempo se constituyen en un referente ético de la sociedad que al "buscar alternativas que impliquen la no repetición de actos similares en

\footnotetext{
a las víctimas de violaciones de la legislación penal, de normas internacionales de derechos humanos y del derecho internacional humanitario perpetradas por grupos armados al margen de la ley", tenía por objeto principal que el Estado asumiera su responsabilidad con las víctimas por medio del pago de las "indemnizaciones que le son debidas por los autores y demás responsables de tales actos" (Artículo 15). Del mismo modo, en el proyecto de ley se reconocía a la víctima como "aquellas personas de la población civil que han sufrido daños, individual o colectivamente, incluidas lesiones físicas o mentales, sufrimiento emocional, pérdidas económicas o menoscabo sustancial de sus derechos fundamentales" (Artículo 15). Dentro del universo de víctimas, el proyecto de ley incluía a los desplazados, secuestrados, menores de edad forzados a participar en el conflicto, y la "familia inmediata" o las personas a cargo de la víctima directa. Adicionalmente, se establecía que "una persona será considerada víctima con independencia de si el autor de la violación ha sido identificado, aprehendido, juzgado o condenado y de la relación familiar que pueda existir entre el autor y la víctima" (Artículo 15).

El proyecto de ley consideraba también el reconocimiento "simbólico" de las víctimas como una forma de honrarlas, por medio de "la Orden de Reconocimiento de las Víctimas de la Violencia", de la celebración del "Día Nacional de Solidaridad con las Víctimas de la Violencia", y la creación de la Oficina de Memoria Histórica (Artículos 16, 17 y 18).
} 
el futuro, les otorga una condición de superioridad moral con relación a los autores de los crímenes" (Cepeda y Girón; 2006: 376). En otras palabras, la lucha simbólica y política emprendida por las víctimas se dirige a "una reconceptualización de los significados e imaginarios que se suscitan con el [término]" (Villa, 2007: 27), para así concebir a las víctimas como sobrevivientes y como testigos (en el sentido activo que este último término puede significar), "que dan fe de lo que ha sucedido, que porta la palabra y que tienen una verdad que confronta con la de la historia oficial". De esta forma, la víctima como sobreviviente y testigo activo "se transforma en un actor de la memoria y de la historia" (Villa, 2007: 28).

\section{LOS EFECTOS DE NOMBRAR Y CLASIFICAR: DISCURSOS DOMINANTES Y DISRUPTIVOS}

Bourdieu menciona que la posición de los agentes en el espacio social incide en la visión que estos tienen del mismo: "dado que hemos construido el espacio social, sabemos que los puntos de vista (...) son vistas tomadas a partir de un punto, es decir de una posición determinada en el espacio social" (Bourdieu, 2007b: 132). En particular, las víctimas perciben el campo del Proceso de Justicia y Paz como un espacio social "desequilibrado", "injusto", en el que no son plenamente reconocidas, $y$ en donde sus derechos son constantemente vulnerados.

En términos más concretos, la lucha política y simbólica que se origina en este campo jurídicopolítico se concreta en torno a las dinámicas de inclusión y exclusión del universo de víctimas, y los mecanismos de clasificación o "nominación" que se hacen sobre las mismas para determinar qué agente se encuentra cobijado en esta categorización. Esta clasificación reside a su vez en el discurso oficial como discurso dominante en el que se encuentra inscrito el uso de una violencia de carácter simbólico que continuamente se reproduce en este espacio social.

La violencia simbólica que se genera al interior del campo del Proceso de Justicia y Paz es posible debido a la existencia de un capital simbólico que posee el gobierno, y que emplea para "clasificar y construir los grupos sociales", en este caso para delimitar el universo de víctimas y para configurar un tipo especial de victimario como el desmovilizado. Incluso, el ejercicio de la violencia simbólica, que se sustenta en la posesión de un capital simbólico, es una "lucha de clasificaciones, como lucha propiamente simbólica (y política), para imponer una visión del mundo social, o, mejor aún, una manera de construirlo" (Bourdieu, 2002: 24). En relación a este punto, la lucha simbólica y política emprendida por las víctimas por ser adecuadamente reconocidas e incluidas dentro de su vasto universo, se inscribe también en el debate alrededor del uso y los abusos de la noción de víctimas y del discurso de la reconciliación que han producido determinadas implicaciones políticas y efectos discursivos dominantes y de ruptura provenientes de los agentes implicados.

En relación con lo anterior, "la lucha simbólica por el poder de producir y de imponer la visión del mundo legítima" permite dar cuenta de un poder simbólico como un "poder de hacer 
cosas con palabras" (Bourdieu, 2007c: 141), esto implica una lucha constante que se crea alrededor de las clasificaciones, que son impuestas en esta Ley, que reflejan el poder de "nominación oficial" que detenta el Estado para categorizar quién entra en el universo de víctimas y quién debe ser a su vez reconocido como desmovilizado. Esta nominación oficial, además de ser un poder simbólico, es concretamente "una de las manifestaciones más típicas del monopolio de la violencia simbólica legítima que pertenece al Estado o a sus mandatarios" (Bourdieu, 2007c: 138).

Más aún, en el debate y en las luchas sobre la inclusión de todas las víctimas, incluidas aqueIlas que lo han sido por parte de los agentes del Estado, en el amplio universo en el que son identificados ciertos derechos, las relaciones objetivas de poder al interior del campo de Justicia y Paz "tienden a reproducirse en las relaciones de poder simbólico" y así mismo, la lucha simbólica por la "producción del sentido común (...) o por el monopolio de la nominación legítima" lleva a los agentes, a víctimas y victimarios a emplear su capital simbólico característico para defender e imponer su propia clasificación, acorde con sus intereses y con su visión del espacio social como un "campo de luchas" y como "sistema de relaciones independientes" (Bourdieu, 1995- 2007).

De este modo, en el campo del Proceso de Justicia y Paz que se ha constituido en un espacio social, de lucha política y simbólica por el posicionamiento, también se ha asignado un lugar jurídico y político a las víctimas y a los victimarios, que ha producido una serie de efectos dominantes y disruptivos que en el plano discursivo se pueden identificar a partir de la noción de reconciliación y la que se emplea de víctima como partes centrales de este proceso, y partiendo de la concepción de la Ley como una estrategia jurídica y política de clasificación de víctimas y victimarios, y como un lugar privilegiado de enunciación discursiva empleado por el gobierno.

\section{CONCLUSIONES}

El espacio social constituido a partir de la Ley de Justicia y Paz permite identificar el tipo de luchas que se libran al interior del mismo, que en el caso de las víctimas se encuentran encaminadas a la búsqueda de un mejor posicionamiento que les brinde un adecuado reconocimiento como sujetos jurídicos y políticos, portadores de los derechos a la verdad, la justicia y la reparación. En este sentido, la lucha simbólica por parte de las víctimas se ha dirigido a atacar la invisibilidad y exclusión que se encuentran reflejadas en un universo limitado e incompleto, en el que sólo se incluyen a determinados tipos de víctimas, según una previa clasificación realizada por el detentador del monopolio de la nominación, que en este caso corresponde al Estado. 
De esta forma, la violencia simbólica que se ejerce en este espacio se encuentra reflejada en el poder detentado por el gobierno, que se manifiesta en la posesión de un capital simbólico empleado para clasificar a las víctimas y determinar quiénes entran dentro de su universo.

No obstante, la dimensión simbólica del orden social en la que también y sobre todo es posible "constituir lo dado enunciándolo", se encuentra presente no solo en el deseo e impulso de detentar el poder y de dominar el campo, sino que se extiende igualmente en los propósitos que tienen las víctimas de posicionarse en el mismo. De este modo, el capital simbólico se emplea también para perseguir cambios en el espacio social, reforzando la idea de la permanente reconfiguración del campo, puesto que éste no es un espacio constituido de una vez y para siempre.

Así mismo, la dimensión simbólica del orden social que se representa en la clasificación y construcción de grupos y categorías sociales, carga también el peso de las prenociones o de las categorías preconstruidas; concretamente, para el caso de las víctimas y del Proceso de Justicia y Paz, en la lucha simbólica y política también se disputa la redefinición de esta categoría y su consecuente desnaturalización, en otras palabras, la lucha simbólica que se da en el espacio social es una lucha por los significados de las nociones y de las categorías que han sido impuestas por los detentadores del poder simbólico.

Por último, vale la pena mencionar que al interior mismo del espacio social que se ha configurado alrededor del proceso de justicia y paz, coexisten diferentes órdenes y tipos de politicidad, entendiendo por politicidad los espacios de disputa, la lucha por los significados, la configuración de subjetividades y los recursos discursivos empleados, principalmente.

\section{BIBLIOGRAFÍA}

- Bourdieu, Pierre. (1993). "Entrevista A Pierre Bourdieu: La Lógica De Los Campos", En Revista Zona Erógena, No 16, Buenos Aires, Disponible En http://www.Bdp.Org.Ar/Facultad/Catedras/Cp/Tecadm/La\%2 0l\%F3gica\%20de\%20los\%20campos\%2 2020 Entrevista\%20a\%20Bourdieu.Pdf

- Bourdieu, Pierre. (2002). Razones Prácticas: Sobre La Teoría De La Acción, Barcelona, Anagrama.

- Bourdieu, Pierre. (2007a). La Miseria Del Mundo, México, Fondo De Cultura Económica.

- Bourdieu, Pierre. (2007b). El Sentido Práctico, Buenos Aires, Siglo XXI Editores.

- Bourdieu, Pierre. (2007c). Cosas Dichas, Buenos Aires, Gedisa. 
- Bourdieu, Pierre y Wacquant, Loic. (1995). Respuestas Por Una Antropología Reflexiva, México, Grijalbo.

- Bourdieu, Pierre y Wacquant, Loic. (2005). Una Invitación A La Sociología Reflexiva, Madrid, Siglo XXI Editores.

- Elster, Jon. (2006). Rendición De Cuentas. La Justicia Transicional En Perspectiva Histórica, Buenos Aires, Katz.

- Flachsland, Cecilia. (2005). Pierre Bourdieu Y El Capital Simbólico, Buenos Aires, Campo De Ideas.

- García Villegas, M. (2010). Sociología Y Crítica Del Derecho. México, Fontamara.

- Sarmiento, Fernando. (2008). "Ley De Víctimas: Gato Por Liebre", En: Revista Cien Días Vistos Por El CINEP, No 68, Bogotá, Diciembre.

- Villa, Et. Al. (2007). Nombrar lo innombrable. Reconciliación desde la perspectiva de las víctimas. Programa Por La Paz CINEP, Bogotá, Cordaid, Caritas Suiza, Manos Unidas.

- Van Dijk, Teun. (1993). "Principles of Critical Discourse Analysis", En: Discourse and Society, Vol. 4 (2), Pp.: 243- 283.

- Van Dijk, Teun. (1999). "El Análisis Crítico del Discurso", En: Anthropos, Barcelona, 186, Septiembre- Octubre, Pp.: 23- 36, Disponible En Http:/Www.Discursos.Org/Oldarticles/ El\%20an\%E1 lisis\%20cr\%Edtico\%20del\%20discurso.Pdf, Consultado El 26 de Noviembre de 2009.

- Van Dijk, Teun. (2002). "El Análisis Crítico del Discurso y el pensamiento social", En: Athenea Digital, No 1: 18- 24, Disponible En Http://Antalya.Uab.Es/Athenea/Num1/Vandijk.Pdf, Consultado El 26 de Noviembre de 2009. 